\title{
Creatinine and urea biosensors based on a novel ammonium ion-selective copper-polyaniline nano-composite
}

\author{
M. Zhybak ${ }^{\mathrm{a}, \mathrm{b}}$, V. Beni ${ }^{\mathrm{b}, *}$, M.Y. Vagin ${ }^{\mathrm{c}}$, E. Dempsey ${ }^{\mathrm{d}}$, A.P.F. Turner ${ }^{\mathrm{b}}$, Y. Korpan ${ }^{\mathrm{a}, *}$ \\ ${ }^{a}$ Laboratory of Biomolecular Electronics, Institute of Molecular Biology and Genetics, National Academy of Sciences of Ukraine, 03680 Kyiv, Ukraine \\ ${ }^{\mathrm{b}}$ Biosensors \& Bioelectronics Centre, IFM, Linköping University, 58183, Sweden \\ ' Applied Physics Division, IFM, Linköping University, Linköping, 58183, Sweden \\ ${ }^{\mathrm{d}}$ Centre for Research in Electroanalytical Technologies, Department of Science, ITT Dublin, Tallaght, Dublin 24, Ireland
}

\section{A R T I C L E I N F O}

\section{Article history:}

Received 22 July 2015

Received in revised form

29 September 2015

Accepted 3 October 2015

Available online 9 October 2015

\section{Keywords:}

Creatinine

Urea

Amperometric ammonium detection

Copper polyaniline composite

\begin{abstract}
A B S T R A C T
The use of a novel ammonium ion-specific copper-polyaniline nano-composite as transducer for hydrolase-based biosensors is proposed. In this work, a combination of creatinine deaminase and urease has been chosen as a model system to demonstrate the construction of urea and creatinine biosensors to illustrate the principle. Immobilisation of enzymes was shown to be a crucial step in the development of the biosensors; the use of glycerol and lactitol as stabilisers resulted in a significant improvement, especially in the case of the creatinine, of the operational stability of the biosensors (from few hours to at least 3 days). The developed biosensors exhibited high selectivity towards creatinine and urea. The sensitivity was found to be $85 \pm 3.4 \mathrm{~mA} \mathrm{M}^{-1} \mathrm{~cm}^{-2}$ for the creatinine biosensor and $112 \pm 3.36 \mathrm{~mA} \mathrm{M}^{-1} \mathrm{~cm}^{-2}$ for the urea biosensor, with apparent Michaelis-Menten constants $\left(K_{\mathrm{M} \text {,app }}\right)$, obtained from the creatinine and urea calibration curves, of $0.163 \mathrm{mM}$ for creatinine deaminase and $0.139 \mathrm{mM}$ for urease, respectively. The biosensors responded linearly over the concentration range $1-$ $125 \mu \mathrm{M}$, with a limit of detection of $0.5 \mu \mathrm{M}$ and a response time of $15 \mathrm{~s}$.

The performance of the biosensors in a real sample matrix, serum, was evaluated and a good correlation with standard spectrophotometric clinical laboratory techniques was found.
\end{abstract}

(c) 2015 Elsevier B.V. All rights reserved.

\section{Introduction}

Chronic kidney disease (CKD) is a common condition with a high risk of death. The National Health and Nutrition Examination Survey in America has estimated the prevalence of the CKD to be about 16\% (Haynes and Winearls, 2010). One of the main consequences of CKD is a significant increase in the level of metabolic waste products in the blood, including urea and creatinine, that are normally excreted by the kidney (Vaidya et al., 2008). In CKD patients, urea and creatinine levels can reach up to 10 -fold those recorded in healthy patients, rising from 1.7-8.1 mM (Eggenstein et al., 1999) to 50-70 $\mathrm{mM}$ for urea (Walcerz et al., 1998) and from $40-150 \mu \mathrm{M}$ to $1-1.4 \mathrm{mM}$ for creatinine (Ashwood et al., 2006). Consequently, frequent creatinine and urea monitoring, with rapid availability of results, can be expected to be of significant benefit for critically ill patients with remarkable improvement in quality of life for peritoneal dialysis patients (Udy et al., 2009).

Detection of creatinine dates back to the beginning of the 20th century when Jaffe method was developed (Jaffe, 1886). However,

\footnotetext{
* Corresponding authors.

E-mail addresses: valbe@ifm.liu.se (V. Beni), korpan@imbg.org.ua (Y. Korpan).
}

this approach is quite complex, time consuming and has limited sensitivity/specificity. Ongoing demand for simple-to-use, cost effective and decentralised diagnostic tools for clinical practice has significantly boosted the development of alternative methods. In this context, over the past few decades, electrochemical sensors/ biosensors have been making inroads. Among the electrochemical biosensors developed, potentiometric transduction based on the combination of ion-selective electrodes and ammonium ion-generating enzymes, is the most common approach used (Magalhaes and Machado, 2002; Osaka et al., 1998; Radomska et al., 2004a', 2004b). The first example of a potentiometric biosensor for the detection of creatinine was proposed by Meyerhoff and Rechnitz, who used creatinine deiminase (CDI) coupled with an ammonia gas-sensing electrode (Meyerhoff and Rechnitz, 1976). Latter, CDI immobilised in a bovine serum albumin (BSA) (Soldatkin et al., 2002a) and PVA/SbQ membrane (Soldatkin et al., 2002b) was used in combination with ion-sensitive field-effect transistors (ISFETs) for creatinine detection and hemodialysis control (Zinchenko et al., 2012). However, these biosensors suffer from the inherent limitations of potentiometry, i.e. vulnerability to interference from other ions present in the sample solutions, relatively slow response times, and high detection limits in biological fluids (Lad et al. ,2008). 
In order to overcome the limitations of these potentiometric sensors, several authors have explored the use of multiple enzymes systems in combination with amperometric detection. One of the first examples of this approach was proposed in a paper by Tsuchida and Yoda (1983) in which the combination of three enzymes; creatininase, creatinase and sarcosine oxidase, was used for the amperometric detection of creatinine. Electrochemical transduction was achieved via the oxidation of the hydrogen peroxide, generated as part of the enzymatic reaction, at a platinum electrode. A similar enzymatic reaction sequence was explored by Nguyen et al. (1991), who coupled the three-enzyme system with a Clark oxygen electrode. Schneider et al. (1996) and Erlenkotter et al. (2002) reported a poly(carbamoyl)sulfonate (PCS) hydrogel biosensor that presented significant improvement in storage stability (ca. 3 months at $8 \mathrm{C}$ ) and dynamic range. The use of nano-composite electrodes based, for example, on zinc oxide or iron oxide nanoparticles or carbon nano-tubes, has been also explored as a way of improving the performance of these biosensors (Pundir et al. 2013). However, the electrochemical detection of oxygen and/or hydrogen peroxide continued to present several limitations in terms of sensitivity and specificity.

In order to overcome these issues, the use of mediators together with the three-enzyme cascade system was explored. Ramanavicius (2007) was one of the first to report on the use of a mediator, ferricyanide, for a creatine biosensor. This was despite the fact that mediated electron transfer from sarcosine oxidase had been reported by a several authors earlier on (Taniguchi et al., 1988; Turner et al., 1987). However, the dominance of point-ofcare analysers (where sensors are required to be re-used) as opposed to home-use devices for this particular analyte has meant that this approach has not found favour to date. This led authors to explore the use of a four enzyme system in which peroxidase (horseradish peroxidase) was added as biocatalyst for hydrogen peroxide to promote more effective electron transfer (Nieh et al., 2013). Unfortunately, when multiple reactions are run in the same membrane, optimal conditions for each reaction can often not be satisfied and this means that in practice, none of the reactions runs at its optimum in terms of reaction rate and stability (Ricca et al., 2011).

Unlike creatinine biosensors, urea biosensors are commonly constructed using only one enzyme, urease (EC 3.5.1.5), as the biorecognition component, which catalyses the hydrolysis of urea to ammonium and bicarbonate ions (Singh et al., 2008). Among the electrochemical approaches used for urea determination, potentiometry is one of the most popular; several types of transducers, like $\mathrm{CO}_{2}$ electrode (Guilbault and Shu ,1972), ammonia gasselective electrodes (Guilbault and Tarp, 1974), or ISFETs (Munoz et al., 1997; Senillou et al., 1999), have been used to develop potentiometric urea biosensors. Guilbault and Montalo were the first to fabricate a potentiometric urea enzyme biosensor (Guilbault and Shu ,1972; Guilbault and Tarp, 1974) based on a cation-selective glass electrode for detection of ammonium ion activity. The original glass electrode was soon replaced with a more selective, neutral carrier-type ion-selective ammonium electrode (Eggenstein et al., 1999; Walcerz et al., 1998). Given that the enzymatic hydrolysis of urea causes an increase in $\mathrm{pH}$ of the system, $\mathrm{pH}-$ sensitive ISFETs have been widely used for this detection (Dhawan et al., 2009). As already mentioned above, potentiometric approaches pose several drawbacks and to avoid these a number of amperometric urea biosensors have been developed over the last two decades.

Conducting polymers, like polyaniline (PANi) and polypyrole, have become the materials of choice for recent technological advances in amperometric sensors for urea detection. Adeloju et al. $(1996,1997)$ reported on the use of polypyrrole-entrapped urease as an amperometric urea biosensor. The linear range of this biosensor was between 50 and $250 \mu \mathrm{M}$, but it suffered from significant limitations when applied to biological samples, requiring pretreatment with anion exchange separators for the removal of interferants (Rajesh et al. 2005).

Polyaniline-Nafion composites have been used to develop amperometric urea biosensors (Cho and Huang, 1998), both on Au (Luo and Do, 2004) and Pt support electrodes (Stasyuk et al., 2012). Experimental work over the past decade has shown that PANifilm, deposited on a metallic electrode (Au, Pt), and in combination with a cation exchange matrix (Nafion), is highly sensitive to ammonium ions (Strehlitz et al., 2000).

In the current paper, we report the use of a novel ammonium ion-selective composite material, based on polyaniline and copper (Zhybak et al., 2015) for use as a transducer in electrochemical hydrolase-based urea and creatinine biosensors. The experimental designs and analytical performance of the biosensors are detailed together with their application for the determination of creatinine and urea in serum samples from patients with CKD.

\section{Material and methods}

\subsection{Reagents}

Creatinine deiminase (EC 3.5.4.21, microbial, $\geq 25 \mathrm{U} / \mathrm{mg}$ ) was purchased from Sorachim (Spain). Urease (EC 3.5.1.5, from Canavalia ensiformis (Jack Beans), $\geq 600,000 \mathrm{U} / \mathrm{g}$ ), urea, creatinine (anhydrous), hydrochloric acid, copper nitrate, nitric acid, sodium chloride, $\mathrm{KH}_{2} \mathrm{PO}_{4}, \mathrm{Na}_{2} \mathrm{HPO}_{4}, 5 \%$ Nafion ${ }^{\circledR}$ perfluorinated resin solution, glutarealdehyde (GA) (50\% w/v aqueous solution), ethanol, D-Lactitol monohydrate, glycerol, bovine serum albumin (fraction V, 96\%) were purchased from Sigma-Aldrich (Germany). Aniline (99\%) was purchased from Sigma-Aldrich (Germany) and redistilled before use (Important: only freshly prepared aniline should be used for electropolymerisation). Ammonium chloride was purchased from Fluka (Germany). All the chemicals and solvents used were of analytical-reagent grade and used without further purification.

$20 \mathrm{mM}$ phosphate buffer solution (PBS) (prepared by mixing and diluting $20 \mathrm{mM}$ disodium hydrogen phosphate, $20 \mathrm{mM}$ potassium dihydrogen phosphate and $20 \mathrm{mM}$ sodium chloride) $\mathrm{pH}$ 7.4 , was used as the supporting electrolyte during all the electrochemical measurements. The composition of the buffer solution was chosen in order to mimic, in terms of electrolyte composition, those of physiological samples. All solutions were prepared using 18.2 $\mathrm{M} \Omega$ purified water produced using a Simplicity water purification system (Millipore, France). All glassware and polyethylene materials were rinsed with ultrapure water and dried before use.

\subsection{Electrochemical measurements}

All biosensors were built using three-electrode screen-printed platforms (DS C110; "SPE") with a carbon working electrode (4 mm of diameter) a carbon counter and an $\mathrm{Ag}$ pseudo-reference electrode.

Amperometric measurements were performed using a portable potentiostat ( $\mu$ Stat 400, "DropSens", Spain), controlled by the DropView 2.0 software supplied by DropSens and used in accordance with the producer's manual guide. Amperometric detection was performed at $-0.35 \mathrm{~V}$ vs the internal Ag pseudo-reference electrode and under vigorous stirring.

Differential pulse voltammetric measurements (DPV) were carried out using an Autolab model PGSTAT 30 potentiostat/galvanostat controlled with the General Purpose Electrochemical System software programme (Eco Chemie, The Netherlands). DPV measurements were performed according to the following 
protocol: equilibration pretreatment $300 \mathrm{~s}$ at $-0.3 \mathrm{~V}$; measurement potential range: 0.6 to $-0.5 \mathrm{~V}$ (modulation time $0.15 \mathrm{~s}$; interval time $0.6 \mathrm{~s}$; step potential $0.004 \mathrm{~V}$; modulation amplitude $0.01 \mathrm{~V})$. The use of a pretreatment step $(-0.3 \mathrm{~V}$ for $300 \mathrm{~s}$ ) prior to DPV measurement was adopted to improve the reproducibility (SD ca. $4 \%$ for 3 repetitions) of the experimental responses. All DPV measurements were performed without stirring.

Prior to use, the biosensors were soaked in PBS for $30 \mathrm{~min}$ at room temperature to equilibrate the sensing composite. The sensor response to a particular substrate concentration was taken as the average of three separate measurements.

\subsection{Electrode modification with PANi-Nafion-CU composite}

Preparation of the PANi-Nafion-Cu SPE was carried out according to the protocol proposed by the authors and described in detail in a prior manuscript (Zhybak et al. 2015). Briefly: (i) SPEs were modified with $\mathrm{Cu}$ by cyclic voltammetry ( 10 cycles between -0.9 and $0.7 \mathrm{~V}$ at $0.05 \mathrm{~V} \mathrm{~s}^{-1}$ ) in a $0.05 \mathrm{M}$ copper (II) nitrate and $0.1 \mathrm{M} \mathrm{HNO}_{3}$. (ii) Following rinsing thoroughly with distilled water and drying in air for $15 \mathrm{~min}$. The electrodes were drop-cast with a $2 \mu \mathrm{l}$ aliquot of $2 \mathrm{wt} \%$ neutralised Nafion solution (prepared from $5 \%$ sample by $90 \%$ ethanol/water dilution) and left to dry in air for 15 min. (iii) Finally the PANi layer was electrodeposited from a $0.2 \mathrm{M}$ aniline solution in $0.5 \mathrm{M} \mathrm{HCl}$ by cyclic voltammetry (10 cycles between -0.4 and $1.0 \mathrm{~V}$ at $0.05 \mathrm{~V} \mathrm{~s}^{-1}$ ). The PANi-Nafion-Cumodified SPE was then rinsed thoroughly with distilled water and dried in air for $15 \mathrm{~min}$. All treatments and measurements were carried out at room temperature.

\subsection{Enzyme immobilisation procedure}

Fresh solutions of enzyme were prepared in PBS. The stock

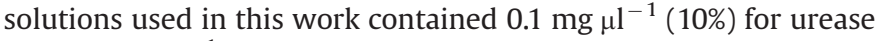
and $0.2 \mathrm{mg}^{-1} \mathrm{l}^{-1}$ (20\%) for creatinine deiminase (CDI). Aliquots of enzyme solution were mixed with PBS containing BSA, lactitol and glycerol to give final concentrations of $2 \%$ for urease and $5 \%$ for CDI, and 5\% BSA, 2\% lactitol and 5\% glycerol. Enzyme immobilisation was performed by drop-casting onto the PANi-Nafion-Cumodified SPE $2 \mu \mathrm{l}$ of a solution of the enzyme. Following dropcasting, the prepared sensor was cross linked in the presence of saturated GA $(25 \% \mathrm{w} / \mathrm{v})$ vapour in an exhaust fume hood at room temperature for $25 \mathrm{~min}$. Prior to use, the biosensors were dried for $1 \mathrm{~h}$ at $4{ }^{\circ} \mathrm{C}$. The functionalised electrodes were then rinsed 3 times with $20 \mathrm{mM}$ PBS and stored in the same buffer at $4{ }^{\circ} \mathrm{C}$ until use.

\subsection{Preparation of serum samples and standard addition assay}

Serum samples from patients with chronic kidney disease were obtained from the Kyiv Research and Practice Centre of Nephrology and Hemodialysis (Kyiv, Ukraine) following the guidelines of the European Group on Ethics in Science and New Technologies of the European Commission (especially No 17, 4th February 2003) and those of the Ethics Committee of the American Psychological Association. The Ukrainian Government personal data protection rules as well as the Ethics Committee of the Institute of Molecular Biology and Genetics NAS of Ukraine rules (approved on 25th April 2012 to conduct the relevant research in the frame of SMARTCANCERSENS Project, PIRSES-GA-2012318053) were followed during collection, delivery and investigation of Human biological samples.

Venous blood ( $2 \mathrm{ml}$ ) was collected in a heparinised cold tube. The tube was centrifuged at $1500 \mathrm{~g}$ for $10 \mathrm{~min}$ and cell-free supernatant removed. All serum samples were kept cold in an ice box during the time between collection and measurement. The assay of creatinine and urea in the serum samples was performed by means of amperometry at $-0.35 \mathrm{~V}$ with the elaborated biosensors using the standard addition method. An aliquot of the serum sample was directly injected into the measuring vessel in order to obtain a 100-500 and a 1000-2000 fold dilution of the serum sample, respectively, for creatinine and urea determination.

Reference data on creatinine and urea concentration in patient serum samples were obtained from a commercial laboratory specialising in medical analyses; concentration of creatinine and urea were obtained by the standard colorimetric assay based on creatininase, creatine amidinohydrolase, sarcosine oxidase multiple enzymatic reactions and urease enzymatic reaction, respectively.

\section{Results and disscussion}

\subsection{Optimisation of the ammonium ion-selective composite for use in biosensors}

The authors recently reported on the development of an ammonium ion-sensitive PANi-Nafion-Cu composite that was shown to be suitable for the voltammetric/amperometric detection of ammonium in serum samples (Zhybak et al., 2015). This composite was also shown not to respond to model primary amine containing biomolecules (BSA) such as creatinine or urea, thus demonstrating its high specificity towards ammonium ions as it can be seen in Fig. S1A. These results were highly significant, in demonstrating that the combination of PANi and copper provides improvement in the selectivity of the sensor compared to other copper-based electrodes, which have been shown to be sensitive to a variety of primary amines (Lin et al., 2011), including creatinine (Chen and Lin, 2012). Furthermore the PANi-Nafion-Cu-nanocomposite showed significant increase in sensitivity when compared to the only Cu or only PANi electrodes (Fig. S1B) (Zhybak et al., 2015). These results indicate the high potentiality of the PANi-Nafion-Cu-nanocomposite to serve as transducer in the development of highly specific creatinine/urea biosensors, based on the appropriate hydrolase enzymes. Hence, to demonstrate this possibility, the development of a creatinine and of a urea biosensor, via the coupling of the PANi-Nafion-Cu-modified SPE with creatinine deiminase or urease, was undertaken and reported in the current manuscript.

\subsection{Immobilisation of enzymes}

The final target of the developed biosensors was the detection of creatinine and urea in serum sample; for this reason physiological $\mathrm{pH}$ (7.4) was chosen to perform all experimental work.

Despite this, prior to continue the biosensors development the influence of $\mathrm{pH}$ on the response of the PANi-Nafion-Cu nanocomposite was performed. As it can be seen from Fig. S2 no significant variations in the response in the $\mathrm{pH}$ range 5-8 (Zhybak et al., 2015) was recorded.

These results, together with the aim of developing the biosensors to work in serum sample forced us to optimise both biosensors for operating at a $\mathrm{pH}$ of 7.4. Conveniently, this also fits well with the optimum working/stability $\mathrm{pH}$ for urease, but unfortunately, this is not the case for the CDI ( $\mathrm{pH}$ optimum 8.5-9.5). In order to improve the operational stability of the enzymes, different strategies for their immobilisation were investigated as part of this work. At first, immobilisation of the enzymes from a 5\% BSA solution in PBS followed by cross linking in saturated GA $(25 \% \mathrm{w} / \mathrm{v})$ vapour was attempted. Stability and performance of the biosensors were evaluated by monitoring their responses, upon measurement of creatinine or urea standard solutions $(5,25$ and $50 \mu \mathrm{M}$ ), over a period of $72 \mathrm{~h}$. The urease-based biosensor presented quite good stability and conversion ability, especially at low 

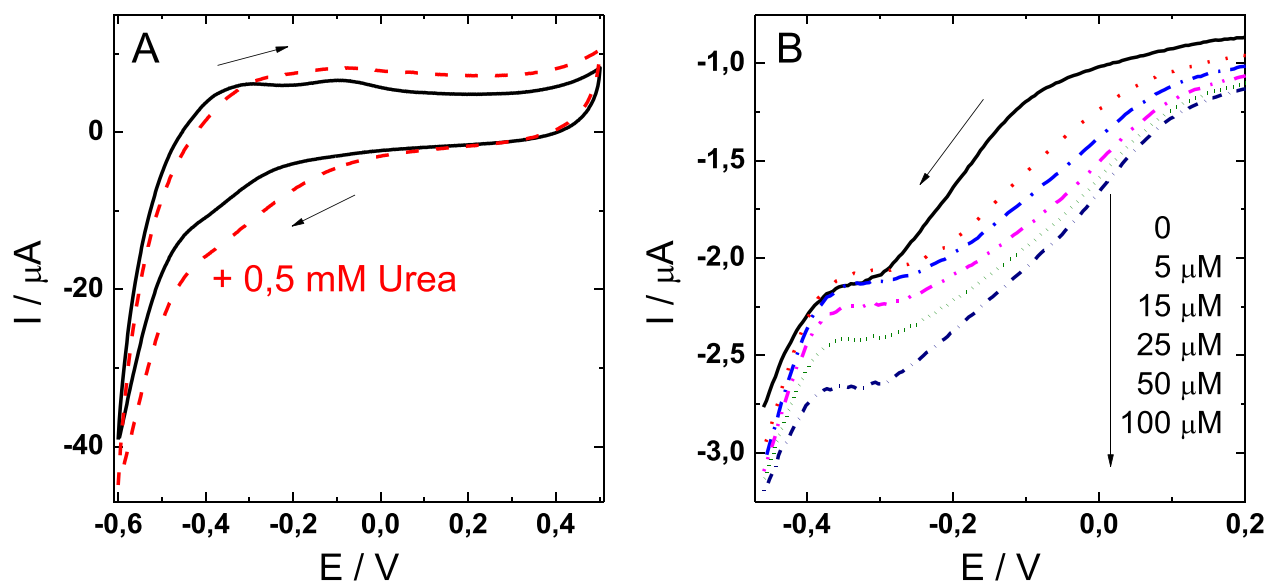

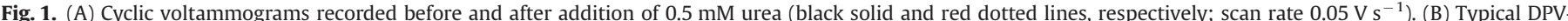

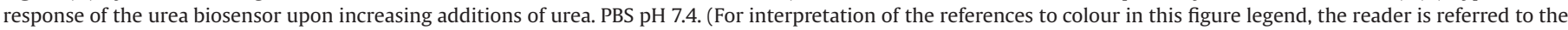
web version of this article.)
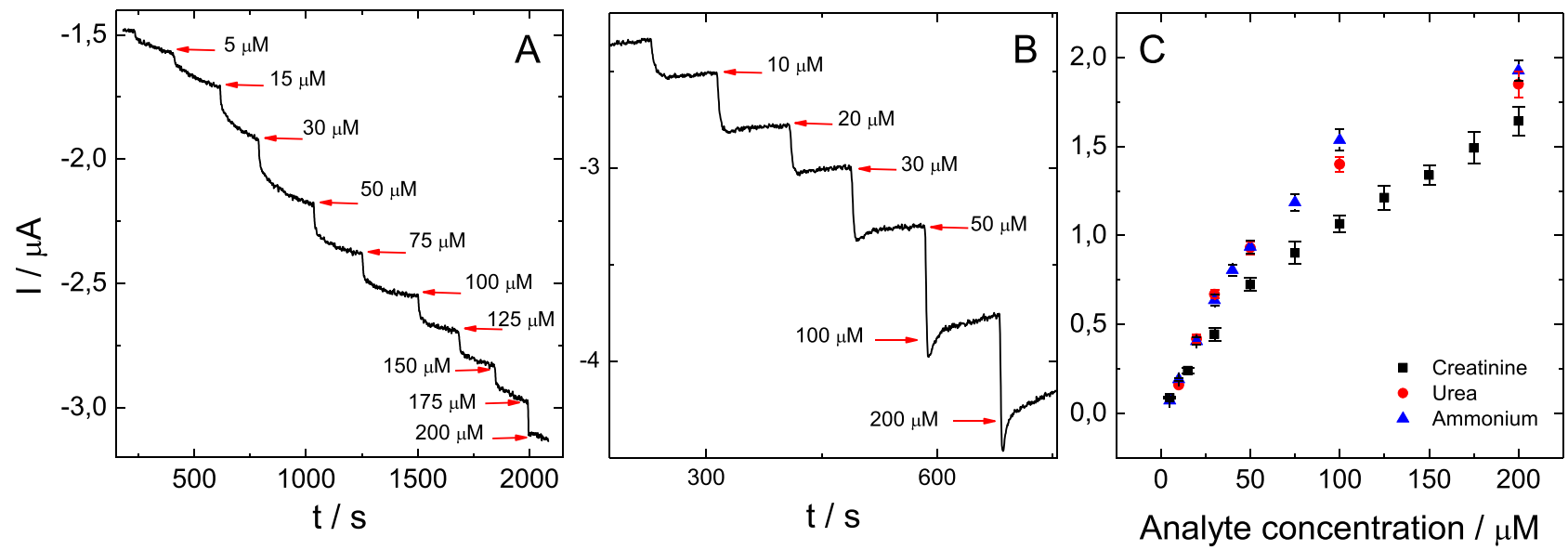

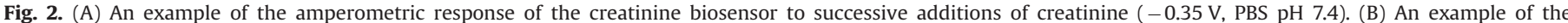

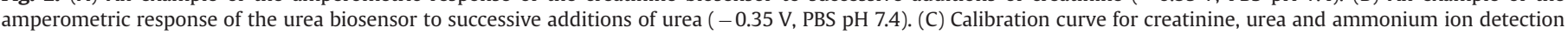
obtained at creatinine and urea biosensors and PANi-Nafion-Cu-modified SPE.

concentrations, but the CDI-based biosensor suffered from high noise, low response and poor stability, with loss of ca. $90 \%$ of its efficiency after $3 \mathrm{~h}$ from preparation (Data not shown). To improve stability (operation and storage) of the enzyme biosensors, the use of D-lactitol monohydrate and glycerol as stabilisers was explored (Gibson et al., 1992). The use of glycerol prevents loss of the enzyme activity during the immobilisation process and results in a better homogeneity and adhesion of the membrane (Zhylyak et al. 1995). D-lactitol and glycerol (2\% and 5\% respectively) were added in both CDI and urease solutions; their use improved considerably the performance of the creatinine biosensor delivering good operation stability over $72 \mathrm{~h}$ (Fig. S3). As can be seen from Fig. S3, no significant loss in the electrochemical response for both the biosensors was recorded over this period.

\subsection{Biosensor performance in model media (PBS $p H$ 7.4)}

The addition of urea or creatinine in the PBS solution resulted in a significant change, in a voltammetric experiment, of both the cathodic and the anodic currents (Figs. 1A and S4). Initially, the use of DPV measurements was investigated as the transduction approach. As it can be seen from Figs. 1B and S5 the addition of increasing concentration of the analytes (creatinine, urea or ammonium) resulted in a significant increase in the cathodic current between -0.15 and $-0.45 \mathrm{~V}$ (vs. Ag pseudo reference electrode).
In order to improve the quality of the analytical response and to gain better understanding of the signal generation process, the use of background compensation was explored (O'Mahony et al., 2005). As it can be seen from Fig. S6(A and B), when the background response (no analyte in the solution) was subtracted from the different curves, a clear cathodic peak appeared between -0.15 and $-0.25 \mathrm{~V}$. In Fig. S6C the calibration results obtained for the creatinine and urea biosensors are reported and compared with those obtained for ammonium.

The similarity of the calibration curves, regardless of the analyte, seems to indicate that the enzyme conversion rate is not the limiting factor in these biosensors. The developed biosensors had linear ranges between 8 and $90 \mu \mathrm{M}$ for creatinine and 5 and 50 for urea, respectively. Sensitivity was estimated to be $95 \pm 6.7 \mathrm{~mA} \mathrm{M}^{-1} \mathrm{~cm}^{-2}$ for the creatinine biosensor and $91 \pm 7.8 \mathrm{~mA} \mathrm{M}^{-1} \mathrm{~cm}^{-2}$ for the urea biosensor.

Despite the fact that the background-subtraction DPV was proved to be rather sensitive, this transduction approach was quite time consuming and operationally complicated; subsequently the use of amperometric measurement was explored.

\subsection{Amperometric assay}

Accordingly to the DPV results $-0.35 \mathrm{~V}$ was identified a suitable generic potential for the detection of the different analytes studied in this work. In Fig. 2A and B the amperometric responses 
to increasing concentrations of creatinine and urea, respectively, are reported. As can be seen, a consistent increase in the cathodic current was observed as a result of increased analytes concentration.

Fig. 2C shows that for both enzyme electrodes, the typical Michaelis-Menten kinetic mechanism, with signal saturation upon the addition of high concentrations of the substrate, was recorded. The apparent Michaelis-Menten constant $\left(K_{\mathrm{M}, \mathrm{app}}\right)$ was calculated from Lineweaver-Burk plot taking into account the current induced by the enzymatic activity and found to be $0.163 \mathrm{mM}$ for CDI and $0.139 \mathrm{mM}$ for urease.

To estimate the conversion level of the target analytes in the biocatalytic layer, the response to ammonium was also evaluated (Figs. 2C and S7). The yield of the enzymatic reactions was calculated from the $I_{\max }$ values obtained from this calibration; the yield of the conversion of creatinine and urea to ammonium was estimated as $83 \%$ and $94 \%$ for CDI and urease, respectively. The relatively low conversion rate can be explained by non-optimal $\mathrm{pH}$ (especially for $\mathrm{CDI}$ ) and temperature (optimal temperature for both enzymes in aqueous solution is ca. $60^{\circ} \mathrm{C}$ ) conditions. GA vapours could also be expected to partly inhibit enzymes during the cross-linking step.

The analytical performances of the developed creatinine/urea biosensors were also evaluated. As can be seen from Fig. 2A and B, the system presented very low background noise (5-8 nA); this facilitated (Fig. 2C) a low limit of quantification (ca. $1 \mu \mathrm{M}$ ) and accurate detection of analytes in the concentration range between $1 \mu \mathrm{M}$ and $125 \mu \mathrm{M}$ for both creatinine and urea. The sensitivities for the biosensors were calculated as $85 \pm 3.4 \mathrm{~mA} \mathrm{M}^{-1} \mathrm{~cm}^{-2}$ for the creatinine biosensor and $112 \pm 3.36 \mathrm{~mA} \mathrm{M}^{-1} \mathrm{~cm}^{-2}$ for the urea biosensor, respectively. The limit of detection $(3 \times \mathrm{SD} /$ sensitivity) was estimated to be $0.5 \mu \mathrm{M}$ for both biosensors. The developed biosensors also had fast response times $(15 \mathrm{~s})$. The standard deviation of the amperometric responses was $8-9 \%$ in the range $1-$ $15 \mu \mathrm{M} ; 6-8 \%$ in range $20-50 \mu \mathrm{M}$ and $5-6 \%$ in the range $75-200 \mu \mathrm{M}$ of creatinine or urea $(n=11)$, respectively.

\subsection{Comparison of biosensor performance}

A comparison of the key analytical characteristics of the developed amperometric creatinine (Table 1) and urea (Table 2) biosensors with those previously decsribed in the literature illustrates that the our biosensors possess higher sensitivity.

\subsection{Creatinine and urea determination in real serum samples}

To demonstrate the suitability of the developed urea and creatinine biosensors for the assessment of analyte concentrations in biological fluids, serum samples from patients with CKD were collected and analysed.

Creatinine and urea detection in serum samples was performed using the amperometric detection technique, via the use of a portable potentiostat ( $\mu$ Stat 400 ), following the standard addition approach. Due to the fact that serum samples were collected from patients with CKD, their dilution with PBS prior to quantification was needed in order to bring the analyte concentrations into the linear range of the biosensors. Dilution factors needed to achieve this goal were estimated using prior clinical/literature data; in the case of creatinine, dilutions of 100-500 fold were decided, while in the case of urea, due to the high concentration of this analyte expected in the patient sample, dilutions of 1000-2000-fold were envisaged. A lower dilution factor was adopted initially; if saturation upon addition of the stock solution of sensor was recorded, the measurement was repeated adopting a higher dilution factor.

The concentrations of creatinine and urea in 5 serum samples from patients undergoing renal dialysis were determined. A typical amperometric response (Figs. S8A and S9A) and the linear approximation curve (Figs. S8B and S9B) for the detection, via standard addition analysis of creatinine and urea, respectively, are reported.

The results obtained with the biosensors showed a very good correlation (slope $\approx 1$ and $R=0.99$ for both biosensors) with the standard spectrophotometric method for creatinine and urea measurement (Fig. 3A and B). Furthermore the RSD ( $R S D=4-8 \%$ for $n=3$ ) of the developed biosensors were comparable with those obtained for the standard spectrophotometric methods $(\mathrm{RSD}=2.5 \%)$. The results obtained demonstrated the possibility of exploiting the proposed biosensors for the amperometric detection of creatinine and urea in serum, which could be used for further development of analytical devices for distributed diagnostics.

\section{Conclusions}

Novel amperometric creatinine and urea biosensors based on a new PANi-Nafion-Cu composite and immobilised hydrolase enzymes (CDI and urease) have been developed and optimised. The biosensors were characterised by a fast response to the analytes (15 s), high selectivity and sensitivity $\left(85 \pm 3.4 \mathrm{~mA} \mathrm{M}^{-1} \mathrm{~cm}^{-2}\right.$ for creatinine and $112 \pm 3.36 \mathrm{~mA} \mathrm{M}^{-1} \mathrm{~cm}^{-2}$ for urea) with a limit of detection of $0.5 \mu \mathrm{M}$ and with $\mathrm{RSD}<8 \%$. The responses of the biosensors were linear over the concentration range $1-125 \mu \mathrm{M}$. The use of glycerol and lactitol in the enzymatic membrane significantly improved the operational stability of the biosensors; this was particularly important in the case of the creatinine biosensor. Measurements obtained with the biosensors correlated well with the standard spectrophotometric laboratory assays for the urea and creatinine in CDK patient serum samples.

Table 1

Analytical characteristics of different amperometric creatinine biosensors.

\begin{tabular}{|c|c|c|c|c|}
\hline & Signal registration mode and sensing component & $L O D(\mu \mathrm{M})$ & Linear range $(\mu \mathrm{M})$ & Sensitivity $\left(\mathrm{mA} \mathrm{M}^{-1} \mathrm{~cm}^{-2}\right)$ \\
\hline Khan and Wernet (1997) & Pt SEC film with cross-linked CA-CI-SOx-enzyme cascade & $1-2$ & $10-5000$ & 23 \\
\hline Schneider et al. (1996) & CA-CI-SOx immobilised in PCS on Pt electrode & 0.3 & $1-150$ & 34 \\
\hline Osborne and Girault (1995) & CDI immobilised in gas permeable membrane & - & $20-1000$ & 0.001 \\
\hline Tombach et al. (2001) & CA-CI-SOx - cascade immobilised in PCS on Pt electrode & 5 & $5-150$ & 5 \\
\hline Choi et al. (2002) & CA-CI-SOx-enzyme cascade in PVA on Pt electrode & 10 & $10-1000$ & 0.125 \\
\hline Hsiue et al. (2004) & Graft polymerisation of CA-CI-SOx-enzyme cascade on Pt electrode & - & $3.2-320$ & - \\
\hline Shih and Huang (1999) & CDI immobilised on PANi-Nafion-GCE & 0.5 & $0.5-500$ & - \\
\hline This work & CDI immobilised on PANi-Nafion-Cu-modified SPE & 0.5 & $1-100$ & $85 \pm 3.4$ \\
\hline
\end{tabular}


Table 2

Analytical characteristics of different amperometric urea biosensors.

\begin{tabular}{|c|c|c|c|c|}
\hline & Signal registration mode and sensing component & $L O D(\mu \mathrm{M})$ & Linear range $(\mu \mathrm{M})$ & Sensitivity $\left(\mathrm{mA} \mathrm{M}^{-1} \mathrm{~cm}^{-2}\right)$ \\
\hline Bertocchi et al. (1996) & Urease encapsulated in nylon net & 10 & $10-300$ & - \\
\hline Pizzariello et al. (2001) & Urease adsorbed on Graphite-Pt electrode & 3 & $10-250$ & 0.2 \\
\hline Vostiar et al. (2002) & Urease adsorbed on TB/GCE & 200 & $200-800$ & 0.98 \\
\hline Luo and Do (2004) & Urease-PANi-Nafion-Au-ceramic film & 50 & $500-5000$ & $31 \pm 2$ \\
\hline Kuralay et al. (2006) & Urease immobilised in poly(vinyl ferrocenium) matrix & 1 & $1-250$ & - \\
\hline Stasyuk et al. (2012) & Urease-PANi-Nafion-Pt electrode & 3 & $30-300$ & $11.6 \pm 0.05$ \\
\hline Tyagi et al. (2013) & Urease-NiO-NPs-ITO-glass & - & $830-16650$ & 21.33 \\
\hline This work & Urease immobilised on PANi-Nafion-Cu-modified SPE & 0.5 & $1-100$ & $112 \pm 3.36$ \\
\hline
\end{tabular}
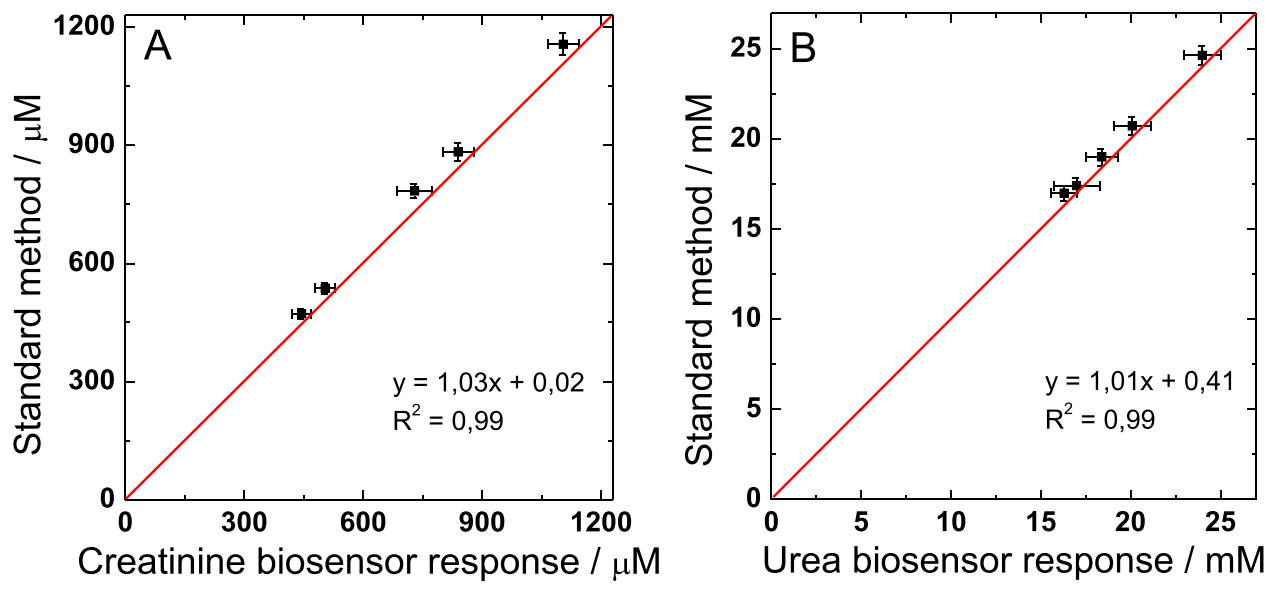

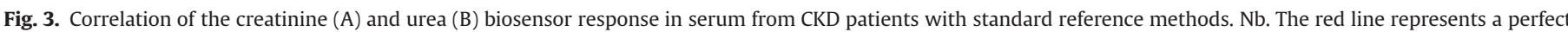
correlation. (For interpretation of the references to colour in this figure legend, the reader is referred to the web version of this article.)

\section{Acknowledgement}

This work was partially funded by the "SMARTCANCERSENS" project from the European Communities Seventh Framework Programme under the Grant Agreement PIRSES-GA-2012-318053 and by the NATO Science for Peace (SFP) Project CBP.NUKR.SFPP 984173.

\section{Appendix A. Supplementary material}

Supplementary data associated with this article can be found in the online version at http://dx.doi.org/10.1016/j.bios.2015.10.009.

\section{References}

Adeloju, S.B., Shaw, S.J., Wallace, G.G., 1996. Polypyrrole-based amperometric flow injection biosensor for urea. Anal. Chim. Acta 323 (1-3), 107-113.

Adeloju, S.B., Shaw, S.J., Wallace, G.G., 1997. Pulsed-amperometric detection of urea in blood samples on a conducting polypyrrole-urease biosensor. Anal. Chim. Acta 341 (2-3), 155-160.

Ashwood, E.R., Bruns, D.E., Burtis, C.A., Tietz, N.W., 2006. Textbook of Clinical Chemistry and Molecular Diagnostics. Elsevier/Saunders, St. Louis, MO.

Bertocchi, P., Compagnone, D., Palleschi, G., 1996. Amperometric ammonium ion and urea determination with enzyme-based probes. Biosens. Bioelectron. 11 (1-2), 1-10.

Chen, C.-H., Lin, M.S., 2012. A novel structural specific creatinine sensing scheme for the determination of the urine creatinine. Biosens. Bioelectron. 31 (1), 90-94.

Cho, W.J., Huang, H.J., 1998. An amperometric urea biosensor based on a polyaniline-perfluorosulfonated ionomer composite electrode. Anal. Chem. 70 (18), 3946-3951.

Choi, S.H., Lee, S.D., Shin, J.H., Ha, J., Nam, H., Cha, G.S., 2002. Amperometric biosensors employing an insoluble oxidant as an interference-removing agent. Anal. Chim. Acta 461 (2), 251-260.

Dhawan, G., Sumana, G., Malhotra, B.D., 2009. Recent developments in urea biosensors. Biochem. Eng. J. 44 (1), 42-52.

Eggenstein, C., Borchardt, M., Diekmann, C., Grundig, B., Dumschat, C., Cammann,
K., Knoll, M., Spener, F., 1999. A disposable biosensor for urea determination in blood based on an ammonium-sensitive transducer. Biosens. Bioelectron. 14 (1), 33-41.

Erlenkotter, A., Fobker, M., Chemnitius, G.C., 2002. Biosensors and flow-through system for the determination of creatinine in hemodialysate. Anal. Bioanal. Chem. 372 (2), 284-292.

Gibson, T.D., Higgins, I.J., Woodward, J.R., 1992. Stabilization of analytical enzymes uzing a novel polymer carbohydrate system and the production of a stabilized, single reagent for alcohol analysis. Analyst 117 (8), 1293-1297.

Guilbault, G.G., Shu, F.R., 1972. Enzyme electrodes based on the use of a carbon dioxide sensor. Urea and L-tyrosine electrodes. Anal. Chem. 44 (13), 2161-2166.

Guilbault, G.G., Tarp, M., 1974. A specific enzyme electrode for urea. Anal. Chim. Acta 73 (2), 355-365.

Haynes, R.J., Winearls, C.G., 2010. Chronic kidney disease. Surgery 28 (11), 525-529.

Hsiue, G.H., Lu, P.L., Chen, J.C., 2004. Multienzyme-immobilized modified polypropylene membrane for an amperometric creatinine biosensor. J. Appl. Polym. Sci. 92 (5), 3126-3134.

Jaffe, M., 1886. Über den Niederschlag, welchen Pikrinsäre in normalem Harn erzeugt und über eine neue Reaction des Kreatinins. Z. Physiol. Chem. 10 (5), $391-400$.

Khan, G.F., Wernet, W., 1997. A highly sensitive amperometric creatinine sensor. Analytica Chimica Acta 351 (1-3), 151-158.

Kuralay, F., Ozyoruk, H., Yildiz, A., 2006. Amperometric enzyme electrode for urea determination using immobilized urease in poly(vinylferrocenium) film. Sens. Actuators B: Chem. 114 (1), 500-506.

Lad, U., Khokhar, S., Kale, G.M., 2008. Electrochemical creatinine biosensors. Anal. Chem. 80 (21), 7910-7917.

Lin, M.-S., Chen, C.-H., Chen, Z., 2011. Development of structure-specific electrochemical sensor and its application for polyamines determination. Electrochim. Acta 56 (3), 1069-1075.

Luo, Y.C., Do, J.S., 2004. Urea biosensor based on PANi(urease)-Nation (R)/Au composite electrode. Biosens. Bioelectron. 20 (1), 15-23.

Magalhaes, J., Machado, A., 2002. Array of potentiometric sensors for the analysis of creatinine in urine samples. Analyst 127 (8), 1069-1075.

Meyerhoff, M., Rechnitz, G.A., 1976. Activated enzyme electrode for creatinine. Anal. Chim. Acta 85 (2), 277-285.

Munoz, J., Jimenez, C., Bratov, A., Bartroli, J., Alegret, S., Dominguez, C., 1997. Photosensitive polyurethanes applied to the development of CHEMFET and ENFET devices for biomedical sensing. Biosens. Bioelectron. 12 (7), 577-585.

Nguyen, V.K., Wolff, C.M., Seris, J.L., Schwing, J.P., 1991. Immobilized enzyme electrode for creatinine determination in serum. Anal. Chem. 63 (6), 611-614.

Nieh, C.-H., Tsujimura, S., Shirai, O., Kano, K., 2013. Amperometric biosensor based on reductive $\mathrm{H}_{2} \mathrm{O}_{2}$ detection using pentacyanoferrate-bound polymer for creatinine determination. Anal. Chim. Acta 767, 128-133. 
O’Mahony, A.M., Scanlon, M.D., Berduque, A., Beni, V., Arrigan, D.W.M., Faggi, E., Bencini, A., 2005. Voltammetry of chromium(VI) at the liquid vertical bar liquid interface. Electrochem. Commun. 7 (10), 976-982.

Osaka, T., Komaba, S., Amano, A., 1998. Highly sensitive microbiosensor for creatinine based on the combination of inactive polypyrrole with polyion complexes. J. Electrochem. Soc. 145 (2), 406-408.

Osborne, M.D., Girault, H.H., 1995. The micro water 1,2-dichloroethane interface as a transducer for creatinine assay. Mikrochim. Acta 117 (3-4), 175-185.

Pizzariello, A., Stredansky, M., Stredanska, S., Miertus, S., 2001. Urea biosensor based on amperometric $\mathrm{pH}$-sensing with hematein as a $\mathrm{pH}$-sensitive redox mediator. Talanta 54 (4), 763-772.

Pundir, C.S., Yadav, S., Kumar, A., 2013. Creatinine sensors. Trac-Trends Anal. Chem. $50,42-52$.

Radomska, A., Bodenszac, E., Glab, S., Koncki, R., 2004a. Creatinine biosensor based on ammonium ion selective electrode and its application in flow-injection analysis. Talanta 64 (3), 603-608.

Radomska, A., Koncki, R., Pyrzynska, K., Glab, S., 2004b. Bioanalytical system for control of hemodialysis treatment based on potentiometric biosensors for urea and creatinine. Anal. Chim. Acta 523 (2), 193-200.

Rajesh, Bisht, V., Takashima, W., Kaneto, K., 2005. An amperometric urea biosensor based on covalent immobilization of urease onto an electrochemically prepared copolymer poly(N-3-aminopropyl pyrrole-co-pyrrole) film. Biomaterials 26 (17), 3683-3690.

Ramanavicius, A., 2007. Amperometric biosensor for the determination of creatine Anal. Bioanal. Chem. 387 (5), 1899-1906.

Ricca, E., Brucher, B., Schrittwieser, J.H., 2011. Multi-enzymatic cascade reactions: overview and perspectives. Adv. Synth. Catal. 353 (13), 2239-2262.

Schneider, J., Grundig, B., Renneberg, R., Cammann, K., Madaras, M.B., Buch, R.P., Vorlop, K.D., 1996. Hydrogel matrix for three enzyme entrapment in creatine/ creatinine amperometric biosensing. Anal. Chim. Acta 325 (3), 161-167.

Senillou, A., Jaffrezic-Renault, N., Martelet, C., Cosnier, S., 1999. A miniaturized urea sensor based on the integration of both ammonium based urea enzyme field effect transistor and a reference field effect transistor in a single chip. Talanta 50 (1), 219-226

Shih, Y.T., Huang, H.J., 1999. A creatinine deiminase modified polyaniline electrode for creatinine analysis. Anal. Chim. Acta 392 (2-3), 143-150.

Singh, M., Verma, N., Garg, A.K., Redhu, N., 2008. Urea biosensors. Sens. Actuators B: Chem. 134 (1), 345-351.

Soldatkin, A.P., Montoriol, J., Sant, W., Martelet, C., Jaffrezic-Renault, N., 2002a. Creatinine sensitive biosensor based on ISFETs and creatinine deiminase immobilised in BSA membrane. Talanta 58 (2), 351-357.

Soldatkin, A.P., Montoriol, J., Sant, W., Martelet, C., Jaffrezic-Renault, N., 2002b.
Development of potentiometric creatinine-sensitive biosensor based on ISFET and creatinine deiminase immobilised in PVA/SbQ photopolymeric membrane. Mater. Sci. Eng. C: Biomim. Supramol. Syst. 21 (1-2), 75-79.

Stasyuk, N., Smutok, O., Gayda, G., Vus, B., Koval'chuk, Y., Gonchar, M., 2012. Bienzyme L-arginine-selective amperometric biosensor based on ammoniumsensing polyaniline-modified electrode. Biosens. Bioelectron. 37 (1), 46-52.

Strehlitz, B., Grundig, B., Kopinke, H., 2000. Sensor for amperometric determination of ammonia and ammonia-forming enzyme reactions. Anal. Chim. Acta 403 (12), $11-23$.

Taniguchi, I., Miyamoto, S., Tomimura, S., Hawkridge, F.M., 1988. Mediated electron transfer of lactate oxidase and sarcosine oxidase with octacyanotungstate(IV) and octacyanomolibdate(IV). J. Electroanal. Chem. 240 (1-2), 333-339.

Tombach, B., Schneider, J., Matzkies, F., Schaefer, R.M., Chemnitius, G.C., 2001. Amperometric creatinine biosensor for hemodialysis patients. Clin. Chim. Acta 312 (1-2), 129-134.

Tsuchida, T., Yoda, K., 1983. Multi-enzyme membrane electodes for determination of creatinine and creatine in serum. Clin. Chem. 29 (1), 51-55.

Turner, A.P.F., Karube, I., Wilson, G.S., 1987. Biosensors: Fundamentals and Applications. Oxford University Press, Oxford.

Tyagi, M., Tomar, M., Gupta, V., 2013. NiO nanoparticle-based urea biosensor. Biosens. Bioelectron. 41, 110-115.

Udy, A., O'Donoghue, S., D’Intini, V., Healy, H., Lipman, J., 2009. Point of care measurement of plasma creatinine in critically ill patients with acute kidney injury. Anaesthesia 64 (4), 403-407.

Vaidya, V.S., Ferguson, M.A., Bonventre, J.V., 2008. Biomarkers of acute kidney injury. Annu. Rev. Pharmacol. Toxicol., 463-493.

Vostiar, I., Tkac, J., Sturdik, E., Gemeiner, P., 2002. Amperometric urea biosensor based on urease and electropolymerized toluidine blue dye as a $\mathrm{pH}$-sensitive redox probe. Bioelectrochemistry 56 (1-2), 113-115.

Walcerz, I., Glab, S., Koncki, R., 1998. Potentiometric enzyme electrode in a flow injection system for the determination of urea in human serum samples. Anal. Chim. Acta 369 (1-2), 129-137.

Zhybak, M., Beni, V., Vagin, M.Y., Dempsey, E., Turner, A.P.F., Korpan, Y., 2015. Electrochim. Acta, Submitted for publication.

Zhylyak, G.A., Dzyadevich, S.V., Korpan, Y.I., Soldatkin, A.P., Elskaya, A.V., 1995. Application of urease conductometric biosensor for heavy-metal ion determination. Sens. Actuators B: Chem. 24 (1-3), 145-148.

Zinchenko, O.A., Marchenko, S.V., Sergeyeva, T.A., Kukla, A.L., Pavlyuchenko, A.S., Krasyuk, E.K., Soldatkin, A.P., El'skaya, A.V., 2012. Application of creatininesensitive biosensor for hemodialysis control. Biosens. Bioelectron. 35 (1), 466-469. 